\title{
Şeker mısırda kardeş ve ikinci koçanın koparılmasının taze/körpe koçanın verimine ve bazı özelliklerine etkisi*
}

\section{Effect of removing tiller and second cop on fresh/baby corn yield and some characteristics in sweet corn}

\author{
Burhan KARA ${ }^{1}$, Hülya GÜL ${ }^{2}$, Halef DİZLEK ${ }^{3}$ \\ ${ }^{1}$ Isparta Uygulamalı Bilimler Üniversitesi, Tarım Bilimleri ve Teknolojileri Fakültesi, Tarla Bitkileri Bölümü-Isparta \\ ${ }^{2}$ Süleyman Demirel Üniversitesi, Mühendislik Fakültesi, Gıda Mühendisliği Bölümü-Isparta \\ ${ }^{3}$ Korkut Ata Üniversitesi, Mühendislik Fakültesi, Gıda Mühendisliği Bölümü-Osmaniye \\ Sorumlu yazar (Corresponding author): B. Kara, e-posta (e-mail): burhankara25@hotmail.com \\ Yazar(lar) e-posta (Authore-mail): hulyagul@sdu.edu.tr, hdizlek@ osmaniye.edu.tr
}

\section{MAKALE BILLGİSİ}

Alınıș tarihi 15 Ocak 2018

Düzeltilme tarihi 17 Nisan 2018

Kabul tarihi 17 Nisan 2018

\section{Anahtar Kelimeler:}

Seker misır

Körpe misir

Koçan verimi

Kardeş koparma

\begin{abstract}
öz
Calıșma, șeker mısırda kardes ve ikinci koçanın koparılmasının taze koçan verim ve özelliklerine etkisi ile koparılan kardeşlerde bulunan ikinci koçanın körpe mısır olarak değerlendirme olanaklarını araștırmak amaciyla yürütülmüștür. Denemeler 2014 ve 2015 yıllarında "BATEM TATLI" şeker mısır çeşidi kullanılarak tesadüf blokları deneme desenine göre üç tekerrürlü olarak Isparta'da kurulmuştur. Kardeşler ve ikinci koçanlar körpe mısır olarak koçan püskülü çıkışından itibaren 3. günde, taze tüketim olarak ise süt olum devresin sonunda hasat edilmiştir. Taze ve körpe koçan verim ve özelliklerine kardeş ve ikinci koçan koparmanın etkisi her iki yılda da istatistiksel olarak önemli olmuș, en uzun koçan boyu (2014'de $18.1 \mathrm{~cm}, 2015$ 'de $17.5 \mathrm{~cm}$ ), en kalın koçan çapı (2014'de $37.3 \mathrm{~mm}, 2015$ 'de 34.2 $\mathrm{mm}$ ) ve koçan ağırlı̆̆ (2014'de $206.7 \mathrm{~g}, 2015$ 'de $194.2 \mathrm{~g}$ ) kardeş ve ikinci koçan koparılan uygulamada ölçülmüştür. En yüksek taze koçan sayısı (2014'de 7798.5 adet da $^{-1}, 2015$ 'de 7672.7 adet $\mathrm{da}^{-1}$ ) ve verimi (2014'de $132.4 \mathrm{~kg} \mathrm{da}^{-1}, 2015$ ' $\mathrm{de} 123.6 \mathrm{~kg} \mathrm{da}^{-1}$ ) kontrol uygulamasında belirlenmiștir. En düşük taze koçan değerleri uygulamalara göre değișmiştir. Uygulamalar arasında körpe koçan verim ve özellikleri (körpe koçan sayısı dışında) her iki yılda da istatistiksel olarak önemli olmamıştır. En yüksek körpe koçan sayısı (2014'de 8136.7 adet da ${ }^{-1}$ ve 2015 'de 8025.6 adet da ${ }^{-1}$ ) kontrol uygulamasında sayılmıştır. Sonuç olarak, kardeş ve koparılan ikinci koçanların birinci koçan boyutlarına azda olsa pozitif katkı yaptığı, elde edilen koçanların körpe mısır olarak değerlendirebileceği söylenebilir.
\end{abstract}

\section{ARTICLE INFO}

Received 15 January 2018

Received in revised form 17 April 2018

Accepted 17 April 2018

\section{Keywords:}

Sweet corn

Baby corn

Ear yield

Tiller removal

Food industry

\begin{abstract}
The study was conducted with aim to investigate the effects of removing tiller and second cop on fresh corn yield and its characteristics and also to evaluation possibility as baby corn of this second cop. The field experiments were set up according to a randomized complete block design with three replications using "BATEM TATLI" sweet corn cultivar in 2014 to 2015 years in Isparta. Tillers and second cobs were harvested on the third day of the tasseling period as baby corn while fresh cobs were harvested at the end of their milk stage. Removing of tillers and the second cops were significantly affect the yield and other properties of fresh cobs in the both years. Highest ear length $(18.1 \mathrm{~cm}$ in 2014 and $17.5 \mathrm{~cm}$ in 2015), highest ear diameter (37.3 mm in 2014 and $34.2 \mathrm{~mm}$ in 2015) and highest ear weight (206.7 $\mathrm{g}$ in 2014 and $194.2 \mathrm{~g}$ in 2015) were determined from both the tiller and the second cop removal practices. The highest fresh ear number (7798.5 adet da ${ }^{-1}$ in 2014 and 7672.7 adet da ${ }^{-1}$ in 2015) and yield (132.4 $\mathrm{kg} \mathrm{da}^{-1}$ in 2014 and $123.6 \mathrm{~kg} \mathrm{da}^{-1}$ in 2015) were determined from the control practices. The yield and other properties (except for baby corn number) of baby corn among practices were not statistically significant in both years. The highest baby corn numbers (8136.7 number $\mathrm{da}^{-1}$ in 2014 and 8025.6 number $\mathrm{da}^{-1}$ in 2015) were determined in control practices. As a result, it is said that little providing positive contribution to development of main cob with removing of tillers and the second cob, and its can be evaluated as baby corn.
\end{abstract}

\footnotetext{
* Bu çalışma AGROSYM 2017'de poster olarak sunulmuş ve özeti yayımlanmıştır.
} 


\section{Giriş}

Körpe mısır, koçan püskülü çıkarma devresinde tozlaşmadan hemen önce hasat edilen olgunlaşmamış yenilebilen koçanlara denir (Galinat 1985). Körpe misır genellikle taze olarak tüketilmektedir, fakat dondurulmuş ve konserve olarak da değerlendirilmektedir. Taze, konserve ve dondurulmuş körpe mısır; sandviç, çorbalarda, pizzalarda, pirinç biryani, süslü gevrek hali ile sebze salatalarında, kızartılmış şekilde ve turşu yapımında kullanılmaktadır (Najeeb ve ark. 2011). Mısırın yemlik değeri ve yeşil aksam verimi diğer bütün tahıl türlerinden yüksek olup, körpe misır hasadından sonra kalan sap ve koçan yaprağı gibi yan ürünler taze ot olarak hayvan beslenmesinde kullanılabilmektedir. Körpe mısırın kısa vejetasyon süresine sahip olması nedeniyle gübreleme miktarı, sulama sayısı ve diğer girdileri daha azdır. Bu durum üretim maliyetini düşürmektedir. $\mathrm{Bu}$ özelliği ile münavebe ve ara bitkisi olarak üretim planlamasına alınabilir (Satyanarayana 1997).

Dünyada en fazla körpe mısır üretici ülkeler, Tayland, Sri Lanka, Çin, Tayvan, Zambiya, Güney Afrika, Kostarika, Guetelama ve Honduras'tır (Anonim 2014a). En fazla tüketici ülkeler ise İngiltere, ABD, Hollanda, Kanada, Almanya, Malezya, Tayvan, Japonya ve Avustralya'dır. Tayland dünyada en fazla körpe misır üreten ülkelerin başında gelmektedir. Tayland'da taze, dondurulmuş ve konserve körpe misır, en fazla tüketilen popüler sebzeler arasındadır. Dünya körpe misır ticaretinin yaklaşık \%80'ni tek başına Tayland tarafından yapılmaktadır ve yaklaşık 30 ülkeye körpe mısır, 100 ülkeye ise tatlı mısır ihracatı gerçekleştirmektedirler (Anonim 2014a).

Mısır alt türlerine göre değişmekle birlikte 50-60 gün süresinde hasat edilebilmektedir. Bu özelliği ile ülkemizde tüm bölgelerde ve farklı tarım teknikleri kullanılarak yetiştirilebilir. Örneğin, ara ürün, birlikte ekim, yem bitkisi amaçlı ekilen mısırların körpe koçanları, ikinci koçanlar, kardeşlerin koçan bağlayanları körpe mısır amaciyla hasat edilebilir. Benzeri tarımsal uygulamalar ile daha yüksek ekonomik gelir ve arazinin daha etkili kullanımını sağlamış olur. Şeker mısırının atdişi ve sert mısıra göre dezavantajlarından birisi koçanının daha küçük olmasıdır ve tüketici eğer şeker mısırını tanımıyorsa tercih etmemektedir. $\mathrm{Bu}$ nedenle kardeş ve ikinci koçanların koparılması ile birinci koçana daha fazla besin maddesi gitmesi ve koçanını daha büyük olması hedeflenmektedir. Bu araştırma, kardeşlenme özelliği olan şeker mısırda kardeşlerin ve ikinci koçanın koparılmasının taze koçan boyutlarına ve koparılan kardeşlerde bulunan koçanların ve ikinci koçanın körpe mısır olarak değerlendirme olanaklarını araştırmak amacıyla yürütülmüştür.

\section{Materyal ve Yöntem}

Araştırma, Isparta koşullarında, Batem tatlı şeker mısır çeşidi kullanılarak 2014 ve 2015 yıllarında tesadüf blokları deneme desenine göre 3 tekerrürlü olarak yürütülmüştür. Denemenin yürütüldüğü Isparta ili, 1050 metre rakımlı Akdeniz ile Orta Anadolu bölgesinin geçiş alanında yer almaktadır. Tipik bir karasal iklim hüküm sürmekte, kışları soğuk ve yağışl1, yazları sıcak ve kuraktır. Deneme yılları ve alanına ait iklim özellikleri Çizelge 1'de verilmiştir.

Deneme alanı toprağı killi-tınlı, hafif bazik, kireç oranı yüksek ve organik madde oranı düşük yapıdadır.

Deneme, her iki yılda da Nisan ayının sonunda kurulmuştur. Denemede parsel sira uzunluğu $5 \mathrm{~m}$ ve 4 sira olarak
Çizelge 1. Deneme alanına ait iklim verileri.*

Table 1. Climatic data belong to experimental area.

\begin{tabular}{|c|c|c|c|c|c|c|}
\hline \multirow{2}{*}{$\begin{array}{c}\text { İklim } \\
\text { faktörleri }\end{array}$} & \multirow[t]{2}{*}{ Yillar } & \multicolumn{4}{|c|}{ Aylar } & \multirow{2}{*}{$\begin{array}{l}\text { Toplam / } \\
\text { Ortalama }\end{array}$} \\
\hline & & Mayıs & Haziran & Temmuz & Ağustos & \\
\hline \multirow{4}{*}{$\begin{array}{l}\text { Yağ1ş } \\
(\mathrm{mm})\end{array}$} & 2014 & 107.0 & 42.8 & 0.8 & 10.2 & 160.8 \\
\hline & 2015 & 67.5 & 92.2 & 3.0 & 43.4 & 206.1 \\
\hline & Uzun & 50.8 & 28.4 & 18.4 & 0.8 & \\
\hline & y1llar & & & & & 98.4 \\
\hline \multirow{4}{*}{$\begin{array}{l}\text { Ortalama } \\
\text { sicaklik } \\
\text { (C) }\end{array}$} & 2014 & 14.5 & 19.1 & 23.7 & 23.2 & 20.1 \\
\hline & 2015 & 13.2 & 18.3 & 24.2 & 23.8 & 19.9 \\
\hline & Uzun & 15.6 & 20.1 & 22.3 & 23.9 & \\
\hline & y1llar & & & & & 20.5 \\
\hline \multirow{4}{*}{$\begin{array}{c}\text { Nispi } \\
\text { nem }(\%)\end{array}$} & 2014 & 62.4 & 52.7 & 45.3 & 45.9 & 51.6 \\
\hline & 2015 & 61.1 & 63.5 & 43.9 & 51.0 & 54.9 \\
\hline & Uzun & 50.3 & 53.0 & 45.8 & 44.5 & \\
\hline & y1llar & & & & & 48.4 \\
\hline
\end{tabular}

*Isparta Meteoroloji istasyonundan alınmıstır.

düzenlenmiş, bloklar arasında $2 \mathrm{~m}$, her parsel arasında $1 \mathrm{~m}$ aralık bırakılmıştır. Ekimden önce parsellere markör çekilmiş ve $70 \mathrm{~cm}$ sıra arası ve $18 \mathrm{~cm}$ sıra üzeri mesafede $(70 \mathrm{~cm}$ x $18 \mathrm{~cm})$, her ocağa iki tohum gelecek şekilde $3-5 \mathrm{~cm}$ derinliğe elle ekilmiştir. Çıkıştan sonra her ocakta bir bitki kalacak şekilde tekleme yapılmıştır. Dekara $15 \mathrm{~kg}$ azotun $1 / 3$ ekimle, kalan $2 / 3$ bitki diz boyu $(35-40 \mathrm{~cm})$ döneminde amonyum sülfat formunda (\%21), $8 \mathrm{~kg} \mathrm{da}^{-1}$ saf fosfor tamamı ekimle birlikte triple süper fosfat formunda uygulanmıştır. Tohumlar ekimden itibaren damlama sulama sistemi ile sulanmıştır.

Hasat; körpe mısır hasadı, koçan püskülü çıkışından itibaren 3. günde (Bar-Zur ve Saadi 1990) (yaklaşık 55-70 gün arasında) ve taze koçan hasadı ise süt olum devresinin sonuna doğru hasat edilmiştir. Kardeşler ve ikinci koçanlar (körpe mısır olarak) koçan püskülü çıkışından itibaren 3. günde koparılmıştır. Hasat edilen körpe misırda körpe misır boyu $(\mathrm{cm})$, körpe misır çap1 $(\mathrm{mm})$, tek körpe koçan ağırlığı (g), körpe koçan sayısı $\left(\operatorname{adet~} \mathrm{da}^{-1}\right)$ ve ayrica taze ot verimi $\left(\mathrm{kg} \mathrm{da}^{-1}\right)$, süt olum devresinin sonunda taze koçanlarda ise koçan ağırlı̆̆1 (g), koçan çap1 $(\mathrm{mm})$, koçan boyu $(\mathrm{cm})$, taze koçan sayısı (adet $\mathrm{da}^{-1}$ ) ve taze koçan verimi $\left(\mathrm{kg} \mathrm{da}^{-1}\right)$ ölçümleri yapılmıştır (Gözübenli ve Konuşkan 2009).

Elde edilen veriler, SAS 5.1 istatistik paket programından faydalanılarak tesadüf blokları deneme desenine göre varyans analizleri yapılmış ve ortalamalar arasındaki farklılıklar LSD testine göre karşılaştırılmıştır (Steel ve Torrie 1980).

\section{Bulgular ve Tartışma}

Şeker mısırda kardeş ve ikinci koçanın koparılmasının taze koçan verimi ve koçan özelliklerine etkisi istatistiksel olarak (koçan çapının ikinci yılı hariç) önemli olurken, dekara körpe koçan sayısı dışında, körpe mısır koçan özelliklerini etkilememiştir (Çizelge 2, 3). Koçan boyu, çapı ve ağırlığı bakımından yıllar arasında istatistiksel olarak fark çıkmazken, dekara taze koçan verimi ve taze koçan sayısı birinci yıl ikinci yıldan daha yüksek olmuştur. Bu farklılık birinci yıldaki dekara koçan sayısının daha yüksek olmasından kaynaklanmaktadır. Her iki yılda da (2014 ve 2015) en uzun koçan boyu, çapı ve koçan ağırlığı sırasıyla, $18.1-17.5 \mathrm{~cm}, 37.3-34.2 \mathrm{~mm}$ ve 206.7$194.2 \mathrm{~g}$ ile kardeş ve ikinci koçan koparılan parsellerde, en yüksek taze koçan verimi (132.4-123.6 $\left.\mathrm{kg} \mathrm{da}^{-1}\right)$ ve sayıs (7798.5-7672.7 adet $\mathrm{da}^{-1}$ ) ise kontrol uygulamasından elde edilmiştir. Koçan özelliklerinin en düşük değerleri kontrol uygulamasında, koçan sayısı ve taze koçan veriminin en düşük değerleri ise kardeş ve ikinci koçan koparılan parsellerde belirlenmiştir (Çizelge 2). Toplam taze koçan veriminin 
düşmesi kardeşlerin ve ikinci koçanın koparılması ile açıklanabilir. Park ve ark. (1989) şeker mısırında kardeşlerin koparılması ile koçan boyunun kısaldığı ve koçan çapının ise etkilenmediği bildirilirken, Sencar ve ark. (1999) her iki karakterin de etkilenmediği, Hanna ve Story (1992) tek koçan ağırlığını düştüğünü bildirilmiştir. Yazgan ve Çelik (1992) ise kardeş almanın tek koçan ağırlığını artırdığı tespit edilmiştir. Kara ve Akman (2002) şeker mısırında; kardeşlerin uzaklaştırılması koçan boyunu ve koçandaki tane sayısını etkilemediğini, koçan sayısı ve veriminin düştüğünü bildirmişlerdir.

Araştırmada kardeş + ikinci koçanın koparılmasının körpe koçan özelliklerine etkisi, dekara körpe koçan sayısı dışında istatistiksel olarak önemli olmamıştır. Benzer şekilde yıllar arasında da fark ortaya çıkmamıştır (Çizelge 3). Dekara koçan sayısında ise uygulamalar arasındaki fark her iki yılda da istatistiksel olarak 0.01 düzeyinde önemli olmuştu. Dekara koçan sayısı kontrol uygulamasında (2014'de 8136.7 adet da ${ }^{-1}$, 2015 'de 8025.6 adet $\mathrm{da}^{-1}$ ) kardeş + ikinci koçan koparılan uygulamasindan (2014'de 456.3 adet da $^{-1}, 2015$ 'de 599.5 adet $\mathrm{da}^{-1}$ ) önemli oranda daha yüksek olmuştur. Bu fark kardeşlerin koçan bağlamaması ve çeşidin 2. koçan bağlama özelliğinin düşük olmasından kaynaklanmaktadır. Batem tatlı çeşidinin kardeş sayısı ortalama 3.40 adet /bitki kardeş oluşmuştur. $\mathrm{Bu}$ kardeşler yeşil ot amaciyla hasat edilebilir. Araştırmada kardeş koparma ortalama birinci y1l $3372 \mathrm{~kg} \mathrm{da}^{-1}$, ikinci yıl $3205.8 \mathrm{~kg} \mathrm{da}^{-1}$ yeşil ot elde edilmiştir.

Körpe koçan üretiminde verim kadar koçan özellikleri de pazarlama bakımından büyük önem taşımaktadır. TAS 15042007 kalite sınıflarına göre, "Ektra" sınıf körpe misır uzunluğu 9.0-13.0 cm, I. Sinif 7.0-8.9 cm ve II. Sinif 4.0-6.9 cm olmalidır (Anonim 2014b). Araştırmada körpe mısır koçan boyları 8.2 ile $9.3 \mathrm{~cm}$ arasında değişmiş ve pazarlanabilir sınıfta yer almıştır. Wang (2009) pazarlanabilir körpe mısır boyunun en düşük 4-9 $\mathrm{cm}$, çapının 1.0 ile $1.5 \mathrm{~cm}$ arasında olması gerektiğini bildirmişlerdir. Bar-zur ve Saadi (1990) ideal körpe koçan boyunu 5-10 cm ve çapının 8.5-17.0 $\mathrm{mm}$ olduğunu rapor etmişlerdir. Asaduzzaman (2014) çeşitlere göre değişmekle birlikte körpe koçan boyunun 9.6-10.8 cm, çapının ise 15.0-17.0 $\mathrm{mm}$ arasında değiştiğini tespit etmiştir. Almeida ve ark. (2005), Silva ve ark. (2006), Wang (2009) ve Kara ve ark. (2017) körpe mısırın koçan veriminin çeşitlerin kardeşlenme özelliklerine, morfolojik yapılarına, erkenci ve geççi olmalarına, koçan bağlama sayısı gibi özeliklerine bağlı olarak önemli ölçüde değiştiğini bildirmişlerdir.

Çizelge 2. Şeker mısırda kardeş ve ikinci koçanın koparılmasının taze koçan verimine ve bazı özelliklerine etkisi.

Table 2. Effect on fresh corn yield and some characteristics of tiller and cob removal in sweet corn.

\begin{tabular}{|c|c|c|c|c|c|c|}
\hline \multirow[b]{2}{*}{ Uygulamalar } & \multicolumn{2}{|c|}{ Koçan boyu $(\mathrm{cm})$} & \multicolumn{2}{|c|}{ Koçan çap1 (mm) } & \multicolumn{2}{|c|}{ Koçan ağırlığı (g) } \\
\hline & 2014 & 2015 & 2014 & 2015 & 2014 & 2015 \\
\hline Kontrol & $16.0 \mathrm{~b}$ & $15.3 \mathrm{~b}$ & $34.3 \mathrm{~b}$ & 32.3 & $192.0 \mathrm{~b}$ & $185.5 \mathrm{~b}$ \\
\hline Kardeş koparma & $17.3 \mathrm{ab}$ & $16.4 \mathrm{ab}$ & $35.6 \mathrm{ab}$ & 33.4 & $202.0 \mathrm{a}$ & $190.3 \mathrm{ab}$ \\
\hline $\begin{array}{l}\text { Kardeş ve } 2 \text {. koçanı } \\
\text { koparma }\end{array}$ & $18.1 \mathrm{a}$ & $17.5 \mathrm{a}$ & $37.3 \mathrm{a}$ & 34.2 & 206.7 a & $194.2 \mathrm{a}$ \\
\hline Yillar & 17.1 & 16.4 & 35.7 & 33.3 & 200.2 & 191.0 \\
\hline $\mathrm{LSD}_{\text {uygulama }}$ & 2.10 & 1.17 & 2.50 & ö.d & 8.92 & 6.68 \\
\hline F değeri uygulama & $8.5^{* *}$ & $12.0 * *$ & $15.2 * *$ & 4.0 & $16.6^{* *}$ & $21.0 * *$ \\
\hline C.V $(\%)$ & 7.3 & 4.5 & 5.8 & 6.7 & 7.9 & 6.6 \\
\hline \multirow{2}{*}{ Uygulamalar } & \multicolumn{3}{|c|}{ Taze koçan sayısı (adet da $\left.{ }^{-1}\right)$} & \multicolumn{3}{|c|}{ Taze koçan verimi $\left(\mathrm{kg} \mathrm{da}^{-1}\right)$} \\
\hline & 2014 & & 2015 & 2014 & & 2015 \\
\hline Kontrol & $7798.5 \mathrm{a}$ & & $7672.7 \mathrm{a}$ & $132.4 \mathrm{a}$ & & $123.6 \mathrm{a}$ \\
\hline Kardeş koparma & $7687.6 \mathrm{a}$ & & $7574.6 \mathrm{a}$ & $129.0 \mathrm{a}$ & & $119.0 \mathrm{a}$ \\
\hline $\begin{array}{l}\text { Kardeş ve } 2 \text {. koçanı } \\
\text { koparma }\end{array}$ & $7545.4 \mathrm{~b}$ & & $6807.3 \mathrm{~b}$ & $104.4 \mathrm{~b}$ & & $98.2 \mathrm{c}$ \\
\hline Yillar & 7677.2 A & & $7351.5 \mathrm{~B}$ & $121.9 \mathrm{~A}$ & & $113.6 \mathrm{~B}$ \\
\hline $\mathrm{LSD}_{\text {uygulama }}$ & 125.6 & & 684.3 & 13.8 & & 8.31 \\
\hline F değeri uygulama & $17.4 * *$ & & $20.3 * *$ & $50.3 * *$ & & $42.6^{* *}$ \\
\hline C.V $(\%)$ & 3.5 & & 4.4 & 6.3 & & 8.0 \\
\hline
\end{tabular}

**: $\mathrm{P}<0.01$ seviyesinde önemli, ö.d: önemli değil.

Çizelge 3. Şeker mısırda kardeş ve ikinci koçanın koparılmasının körpe koçan sayısına ve bazı özelliklerine etkisi.

Table 3. Effect on baby corn number and some characteristics of tiller and cob removal in sweet corn.

\begin{tabular}{|c|c|c|c|c|c|c|c|c|}
\hline \multirow[b]{2}{*}{ Uygulamalar } & \multicolumn{2}{|c|}{ Körpe koçan ağırlığı (g) } & \multicolumn{2}{|c|}{ Körpe koçan çapı (mm) } & \multicolumn{2}{|c|}{ Körpe koçan boyu $(\mathrm{cm})$} & \multicolumn{2}{|c|}{ Körpe koçan sayısı $\left(\right.$ adet da $\left.^{-1}\right)$} \\
\hline & 2014 & 2015 & 2014 & 2015 & 2014 & 2015 & 2014 & 2015 \\
\hline Kontrol & 22.3 & 25.6 & 14.9 & 14.1 & 8.9 & 9.3 & 8136.7 a & $8025.6 \mathrm{a}$ \\
\hline Kardeş koparma & - & - & - & - & - & - & - & - \\
\hline $\begin{array}{l}\text { Kardeş ve } 2 . \text { koçanı } \\
\text { koparma }\end{array}$ & 20.5 & 22.8 & 13.6 & 12.7 & 8.2 & 8.7 & $456.3 \mathrm{~b}$ & $599.5 \mathrm{~b}$ \\
\hline Yillar & 21.4 & 24.2 & 14.2 & 13.4 & 8.6 & 9.0 & 4295.2 & 4312.2 \\
\hline LSD uygulama & ö.d & ö.d & ö.d & ö.d & ö.d & ö.d & 1326.2 & 1425.8 \\
\hline F değeri uygulama & 0.1 & 7.0 & 0.1 & 4.0 & 7.2 & 1.0 & $2803.4 * *$ & $3578.4 * *$ \\
\hline C.V $(\%)$ & 2.2 & 1.9 & 4.9 & 2.6 & 1.8 & 7.2 & 3.5 & 5.1 \\
\hline
\end{tabular}

ö.d: önemli değil. 


\section{Sonuç}

Şeker mısırda kardeş ve ikinci koçanın koparılması ile koçan boyu, çapı ve ağırlığını artırırken, taze koçan sayısını ve verimini azaltmışırı.

Koparılan ikinci koçanların körpe mısır boyu, çapı ve ağırlıkları bakımından uygulamalar arasında istatistiksel olarak fark çıkmamış, fakat dekara körpe koçan sayısı kontrol uygulamasında daha düşük olmuştur.

Şeker mısırda kardeşler koçan bağlamamıştır. Bu nedenle körpe koçan hasadı yapılamamıştır. Koparılan bu kardeşler yeşil ot olarak değerlendirilebilir.

Sonuç olarak, koparılan kardeşlerin yeşil ot amacıyla kullanımı, TAS 1504-2007 kalite sinıflarına göre ikinci koçanların körpe mısır olarak değerlendirilebileceği ve aynı zamanda birinci koçan boyutlarına pozitif katkı yaptığı göz önüne alındığında uygulanabilir bir yöntem olduğu söylenebilir.

\section{Kaynaklar}

Almeida IPC, Silva PSL, Negreiros MZ, Barbosa Z (2005) Baby corn, green ear, and grain yield of corn cultivars. Horticulture Brasilia 23: 960-964.

Anonim (2014a) Baby Corn Production, Processing and Marketing in Thailand. Report Submitted to Field Fresh Foods Pvt. Ltd., Gurgaon, India.

Anonim (2014b) Thai Agricultural Standard (TAS 1504-2007) in Baby Corn. http://www.acfs.go.th/standard/download/eng/baby_corn.pdf Erişim 10 Haziran 2014.

Asaduzzaman MD, Biswas M, Islam MDN, Rahman MM, Begum R, Sarkar AR (2014) Variety and N-fertilizer rate influence the growth, yield and yield parameters of baby corn (Zea mays L.). Journal of Agricultural Science 6: 118-131.

Bar-Zur A, Saadi H (1990) Prolific maize hybrids for baby corn. Journal of Horticulture Science 65: 97-100.

Galinat WC (1985) Whole Ear Baby Corn, A New Way to Eat Corn. Proc. Northeast Corn Improvement Conferance 40: 22-27.

Gözübenli H, Konuşkan Ö (2009) Farklı bitki sıklıklarının bazı mısır genotiplerinde körpe koçan (baby corn) verimi ve özelliklerine etkisi. Türkiye VIII. Tarla Bitkileri Kongresi, 19-22 Ekim, Hatay, Poster Bildiriler, s. 573-576.

Hanna HY, Story RN (1992) Yield and super sweet corn as affected by $\mathrm{N}$ application timing plant density, tiller removal and insecticides proc. flo. State Horticulture Science 105: 343-344.

Kara B, Akman Z (2002) Şeker mısırında (Zea mays saccharata Sturt.) koltuk ve uç alma ile yaprak sıyırmanın verim ve koçan özelliklerine etkisi. Akdeniz Üniversitesi Ziraat Fakültesi Dergisi 15: 9-18.

Kara B, Gündüz A, Işık C, Şener A (2017) Farklı mısır (Zea mays L.) alt türlerinin körpe misır özelliklerinin karşılaştırılması. Uluslararası Tarım ve Yaban Hayatı Bilimleri Dergisi 3: 95-99.

Najeeb S, Rather AG, Sheikh FA, Ahanger MA, Teli NA (2011) Baby corn (Zea mays L.): A means of crop diversification under temperate conditions of Kashmir. Maize Genetics Cooperation Newsletter Vol. 85.

Park KY, Kang YK, Park SU, Moon HG (1989) Effects of planting density of tiller removal on growth and yield of sweet corn hybrids. Field Crop Abstract 43: 723-724.

Satyanarayana E (1997) Business line and the India. Information January 16. 1997.

Sencar Ö, Gökmen S, Sakin MA, Ocakdan M (1999) Şeker mısırında (Zea mays saccharata Sturt) koltuk almanın verim ve bazı özelliklere etkileri. Türkiye 3. Tarla Bitkileri Kongresi, 15-18 Kasim 1999, Adana, Cilt: I, s. 456-459.
Silva PS, Silva PI, Sousa AK, Gurgel KM, Filho IP (2006) Green ear yield and grain yield of maize after harvest of the first ear as baby corn. Horticulture Brazilian 24: 151-155.

Steel RGD, Torrie JH (1980) Principles and Procedures of Statistics. McGraw-Hill Book Company, Inc., New York, USA.

Wang Z (2009) Effect of different schedules of baby corn (Zea mays L.) harvests on baby corn yield, grain yield, and economic profit value. Western Kentucky University, Masters Theses \& Specialist Projects. Paper 131.

Yazgan A, Çelik F (1992) Dört farklı mısır (Zea mays L.) çeşidinde kardeşlenme özelliği ve kardeşlerin alımının verim ve kaliteye etkisi üzerinde ön çalışmalar. C.Ü Tokat Ziraat Fakültesi Dergisi 9: 286-294. 